\title{
سياسة لينين الخارجية تجاه العالم الاسلاهي
}

م.م. قابل محسن كاظمه

مديرية تربية ذيى قار

\section{| - |المقدهة}

اتجه لبنين الى تطبيق سياسة خارجية تنسجم مع مصالح الثعب الروسي بعد نجاح الثورة الروسية في

تشرين الثاني VI9 (19، فقد وجه سياسته الخارجيـة نحو مبدأ (التعايش السلمي) مـع جميع دول العالم، وصسار هذا المبدأ يعرف بالنظرية اللينينية، ويعد اساس السياسة الخارجية الروسية، مع الاخذ بنظر الاعتبار ان تلك

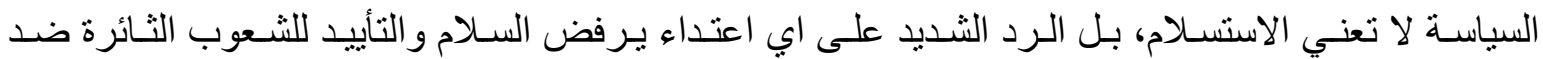
السيطرة الاستعمارية. وكان لسياسته تجاه العالم الاسلامي اهمية كبرى في مطالبة تلك الدول في التحرر من الاستعمار، ما ترتب عليه قيام الثورات في عدد من دول العالم الاسلامي، ومناصرته لهم ماديا ومعنويـا سواء اكان ذلك في العر اق و اير ان او في افغانستان، فضـلا عن اتجاهـه الىى عقد الاتفاقيات الثنائية مـع تلك الدول التي ركزت على تقديم المساعدات الروسية لدول العالم الاسلامي.

\section{سياسة لينين الخارجية تجاه العالم الإسلاهي :}

وجه رسالة إلى العمال المسلمين كافة في العالم طالباً منهم مناصرة الثورة الروسية وتأييدها، فضلاً عن تأييد دعوته للسلام(') ، كما وجه نداءً إلى جميع مسلمي روسيا والثرق في كانون الاول VI9 (9 الك أكد فيه حقهم في ممارسـة معتقداتهم، وحث العرب و الأثر الك والفرس على طرد القوى الأستعمارية من بلدانهم(؟)، مؤكداً على العيش بحرية وسلام، إذ قال: "لكم الحق في بنـاء حياتكم الوطنيـة بحريـة دون ان يقف شيء في

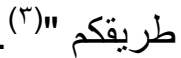

تمكنت الدولـة العثمانيـة مـن خـلال معاهدة بريست ليتوفسك عـام 19 19 وبمسـاعدة ألمانيـا مـن اعـادة باطوم وقارص و اردهان من روسيا، ولم يكن هذا التنازل يعني شيئاً بالنسبة إلى روسيا لأنها فقدت السيطرة عليهاء)، وبعد نهاية الحرب العالمية الأولى عام ^19 19 هيمنت الدول الأوربية على أر اضي الدولـة العثمانية، وصـارت معاهدة بريست ليتوفسك التي حددت العلاقة بين الدولـة العثمانيـة وروسيا لاغيـة(ه)، لكن ظهور الحركة الوطنية التركية التي سـاعدت على قيام (المجلس الوطني الكبير) بزعامـة (مصطفى كمال)(ج) تبنت سياسـة التقرب مـن روسيا، إذ كانت الدولتنان تو اجهان تحدياً مصيرياً فرضـه عليهمـا عدو مشترك فصـار لقاؤ هما امر آ لابد منه(Y)، بسبب حاجة مصطفى كمال للمساعدات الروسية، وحاجة روسيا للدولـة العثمانيـة في كسر الحصار الأقتصادي الذي فرضته الدول الغربيـة عليها، والحيلولة دون وصـول اســلحة الدول الغربيـة

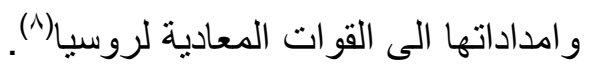

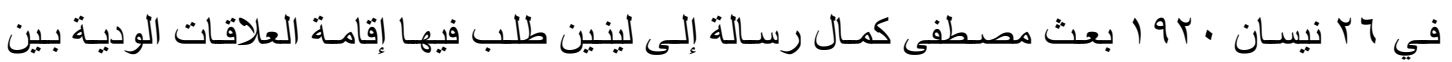

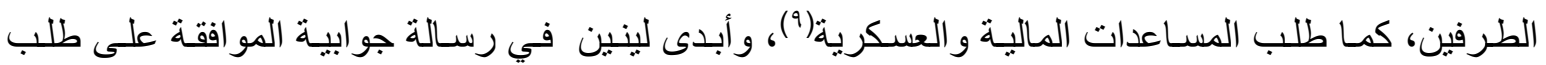
مصطفى كمـال مؤكداً فيهـا بـأن الحكومـة الروسية تمد يـد الصداقة و العون إلى شعوب العـالم كافـة المُطالبـة 
بالسيادة و الإستقلال، كما أكدت الرسالة أن الحكومـة الروسية يسعدها توحيد شعبي الدولة العثمانيـة وروسيا،

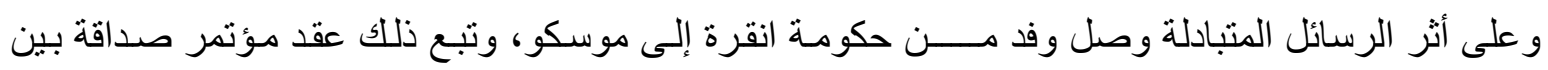

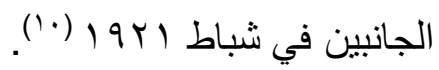

أدى توثيق العلاقة بين الطرفين إلى الإتفاق على عقد معاهدة بينهما، فكانت معاهدة (الصداقة والإخوة)

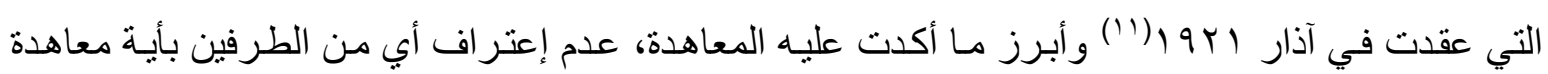

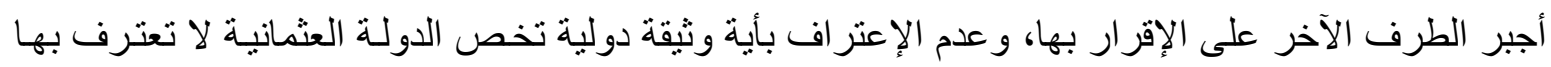

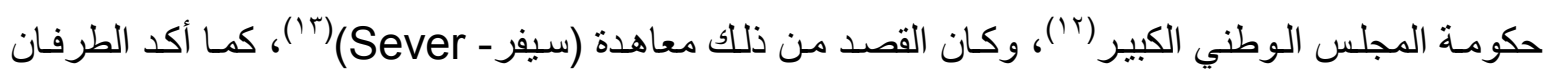
الغاء المعاهدات التي عقدت بينهـا سـابقاً، وصسارت بموجب المعاهدة قارص واردهـان ضـمن حدود الدولة

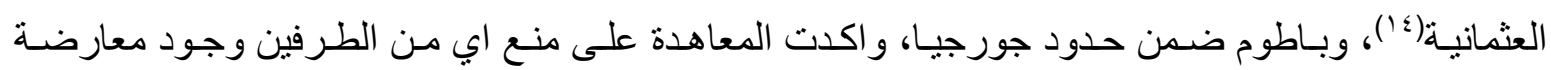
للطرف الاخر على اراضيه(10).

نجحت سياسة لينين الخارجية في عقد تلك المعاهدة، التي جلبت لروسيا الإستقرار في منطقة لها أهمية

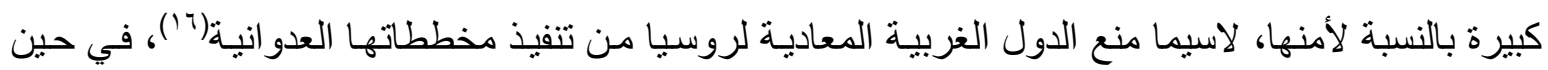

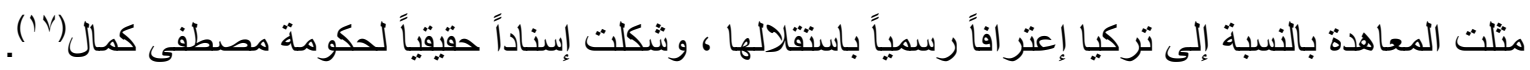
حقق لينين من خـلال هذه المعاهدة تطوراً أقتصسادياً لروسيا سـاعد إلى حد معين في معالجـة بعض التض المشاكل الأقتصادية في البلاد، إذ أدت المعاهدة إلى تطور وسائل الإتصال بين البلدين، سواء كانت بـالتلغر اف لف

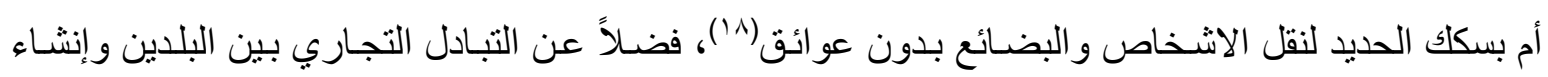
(البيت التجاري الروسي-التركي) الذي كانت مهنه تنظيم تصدير البضائع بين البلدين واستير ادها(9). وقبل افتتاح مؤتمر لوزان أكد لينين في برنامج حكومته أحقية الدولة العثمانية في غلق مضـائقها وقت

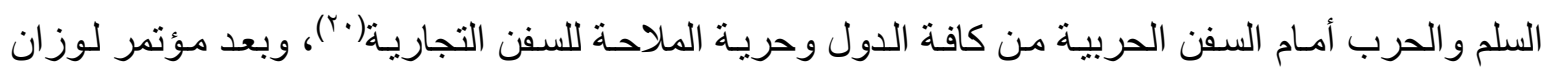
تر اجعت الدولة العثمانية في علاقاتها مع الإتحاد السوفييتي، وأخذت تميل بإتجاه الغرب، ولكن لينين تمسك وحك

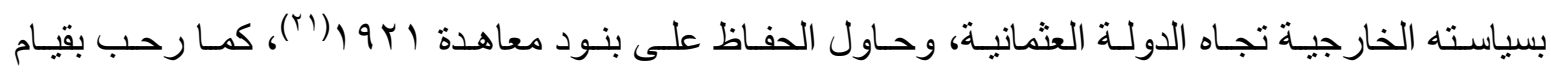
مصطفى كمال بإلغاء الخلافة العثمانية عام بr9 أو وإعلان الجمهورية التركية، و عدّ ذلك تقدماً في برقيته التي أرسلها إلى الحكومة التركية و هنأ فيها الثعب التركي، ودعا الحكومة إلى تعزيز التعاون و التقارب مع الاتحاد

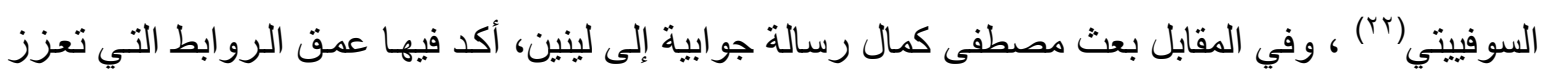
مستقبل البلدين بما فيه مصلحة الشعبين وسعادتهما (rاب). أدى تبادل الرسائل بين الطرفين إلى اعادة العلاقات بينهـا، و إتجـه الطرفان إلى تحسين علاقاتههـا

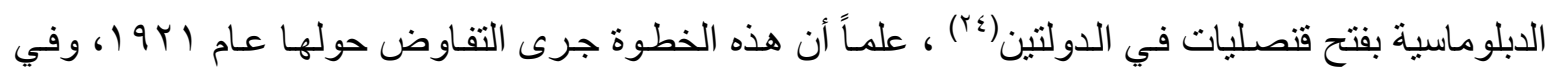

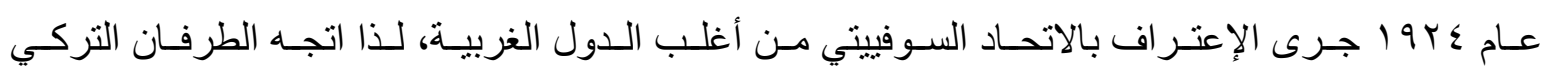
و السـوفييتي إلى تأسيس القنصليات فتمكن السـوفييت من فتح قنصلية في استانبول واخرى في وازمير ،

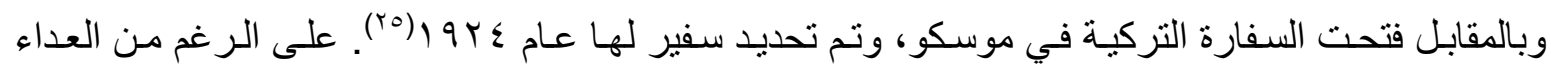
التاريخي بين روسيا والدولة العثمانية، لكن مصلحة البلدين الخاصة إقتضت بأن يحصل تقارب تاريخي بينهما 
فتمكنا من النجاح في تحسين علاقاتهما على الضد من الدول الغربيـة، وبذلك فـإن السياسـة الخارجية لم تتقيد بحدود معينة بل بمصالح تلك البلدان.

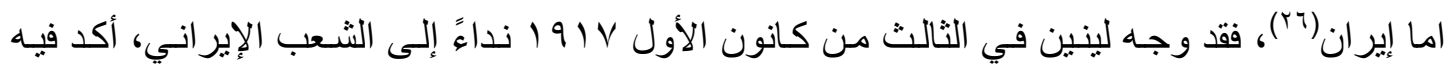
عزم روسيا سحب قو اتها العسكرية الموجودة في إيران بعد ايقاف العمليات العسكرية، وترك الخيار للثـعب الإير اني في تقرير مصيره، وبعد بدء المفاوضـات مـع ألمانيا لعقد إتفاقية بريست ليتوفسك؛ سحبت روسيا

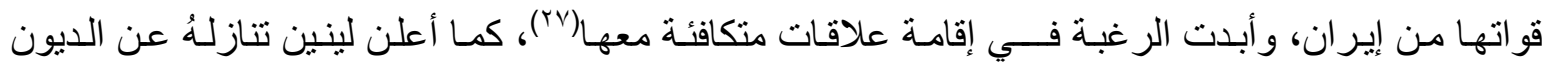

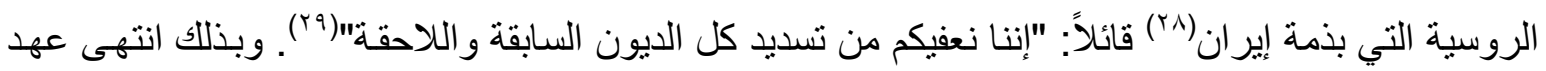
التدخل الروسي في إيران، لكنه خلق فر اغاً ملاه جيش المملكة المتحدة فيما بعد. أمر لينين وزير خارجيته تروتسكي بإبلاغ القائم بالأعمـال الإيراني في موسكو بـان إتفاقيـة (روسيا-

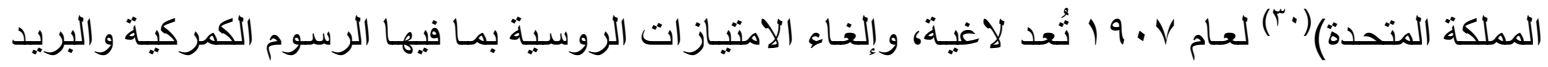

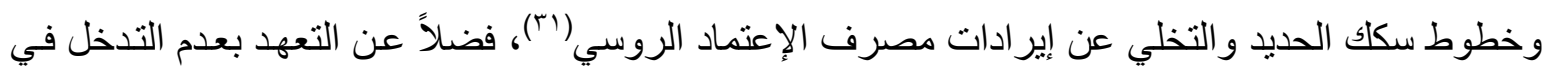
الثؤون الداخلية الإيرانية(rr)، كما أمر لينين بنشر المعاهدات و الوثائق السرية الخاصة باير ان التي إتفقت فيها الحكومة القيصرية وحكومة المملكة المتحدة على تقسيم إيران بعد الحرب العالمية الأولى (זr). وفي • ب كانون الأول VI9 ا ردت الحكومسة الإيرانيـة على المذكرة الروسية، بمذكرة أعلنت فيها إستعدادها للدخول في مفاوضـات مـع الحكومـة الروسية لعقد معاهدة تقوم على أسـاس مبدأ الإتفاق الحرك، و الإحتر ام المتبادل، و عدم التدخل في الثؤون الداخلية(؟r). بعد وصول رد الحكومة الإير انية، أمر لينين بتشكيل وفد للتفاوض معها، وكان الوفد برئاسـة (فيودور

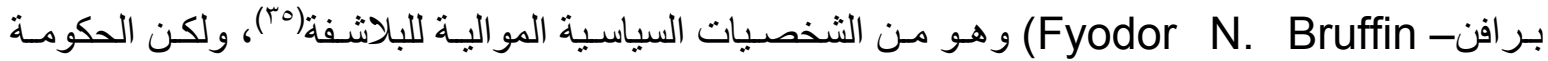
الإير انيـة لـم تحسن استقبال الوفد، ورفضـت الإعتـر اف بـه، على العكس مـن الأوسـاط الثـعبية والأحـزاب السياسية التي رحبت به(بr). ويمكن أن نعزو ذلك إلى خوف الحكومة الإير انية من المملكة المتحدة التي حلت محل روسيا في السيطرة على إيران أولاً، وتخوف الحكومة الإيرانية من انتشـار الافكار الثيوعية في إيران ثنانياً. .

وللحيلولة دون تحول إيران إلى قاعدة لتدخل الدول الغربية ضد روسيا، عمل لينين كل مـا في وسعه

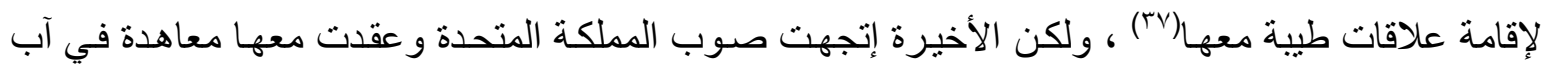

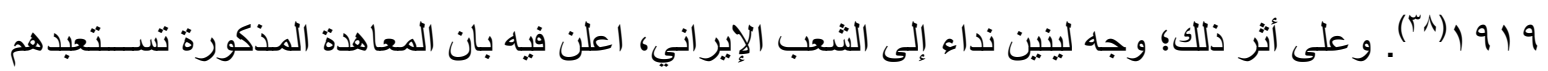

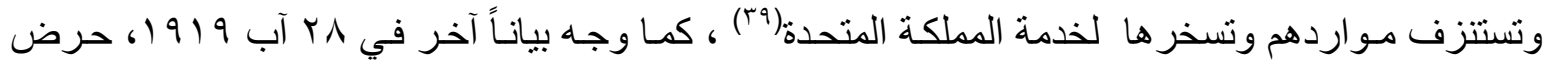
فيه الثعب الإير اني على رفض المعاهدة وعدم الإعتر اف بها، و عرض على الحكومـة الاير انيـة عقد معاهدة متكافئة)(•)

عملت المملكة المتحدة على جعل شمال إيران مركزاً لتجميع المعارضـة الروسية، ودعمتهم بالأسلحة

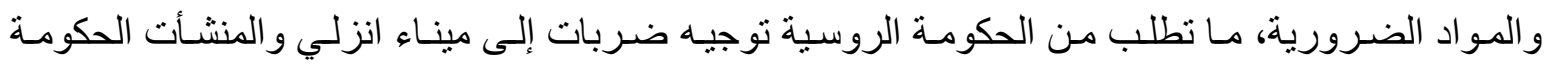




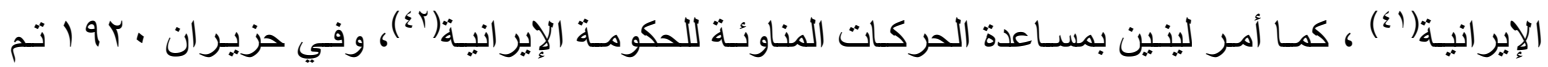

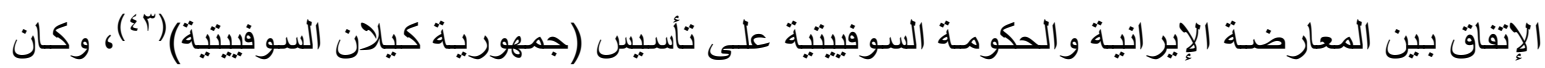
هدف لينين من هذه الاجر اء الضـغط على الحكومـة الإير انيـة للمو افقـة على اجر اء مفاوضـات لعقد معاهدة

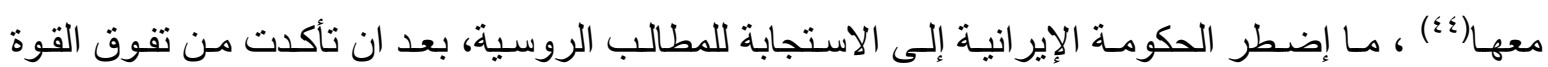

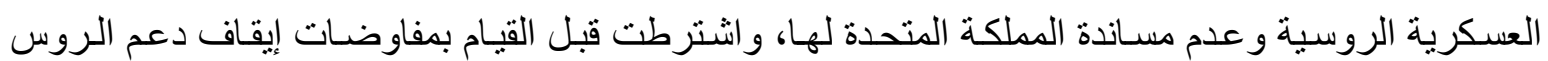
لجمهورية كيلان السوفييتية(0؛)، وبذلك تكللت جهود السياسـة الخارجية الروسية بالنجاح في إجبار الحكومـة الإير انية على البدء بالمفاوضـات للتوصل لعقد معاهدة، وفي مؤتمر السوفييتات الثامن لعامـة روسيا رحب إبـ لينين بالمفاوضات مع إيران و عقد معاهدة معها، إذ فال: "نرحب بـالتوقيع العتيد على معاهدة مـع إيران التي

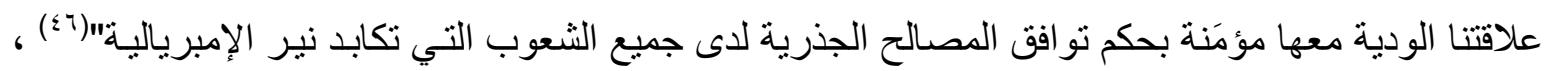
لكن إضطر اب الأوضاع السياسية في إيران عام ابr 19 حسال دون توقيع تلك المعاهدة، لاسيما بعد الإنقلاب

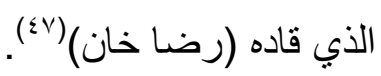

رحب لينين بالانقلاب الإير اني، و عدَّه بداية عهد جديد في العلاقات الروسية الإيرانية، لانه كان يرى

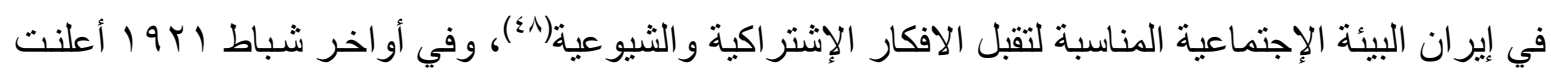
حكومة الانقلاب الغاء معاهدة 9191 المعقودة مع المملكة المتحدة، ما فسح المجال أمام روسيا في التقرب من

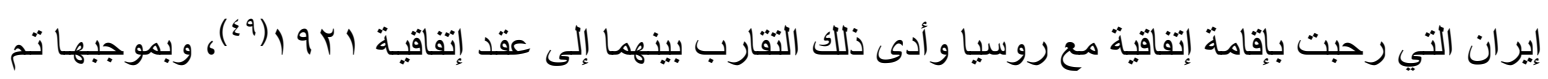
الغاء الاتفاقيات الموقعة بين الطرفين قبل الثورة الروسية، ونقل ملكية المؤسسـات الاقتصـادية في ايران من

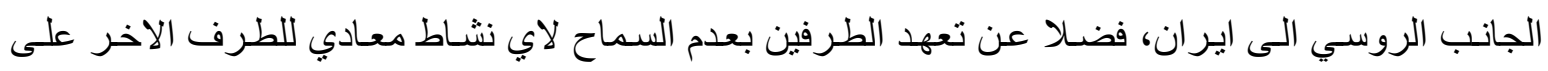

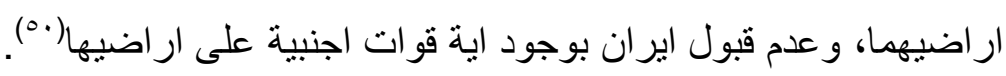

وبموجب المعاهدة تم تجاوز تر اكمات الماضس، لكن إيران سر عان مانقضتها في مواقع عديدة كان أبرز ها عام r 9 (، عندما منحت (شركة ستاندر اويل- stander Oil Co) الامريكية الحق في التنقيب و الإستثمار للنفط في شمالي إيران، وهذا يتناقض مع المادة الثالثة عشر من معاهدة ابY I التي أكد على الغاء إمتياز ات روسيا القيصرية السابقة بشرط أن لا تمنح إلى دولة ثالثة أو شركات تابعة لهاب(ان). وفي الجانب الدبلوماسي، أمر لينين بتعيين سفير لروسيا السوفييتية في طهران وفتحت العديد من

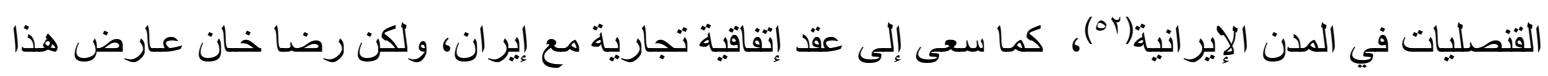

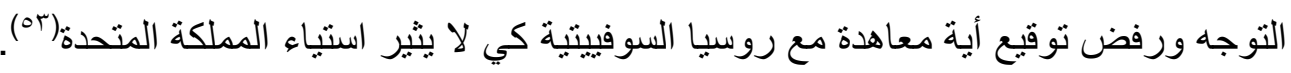

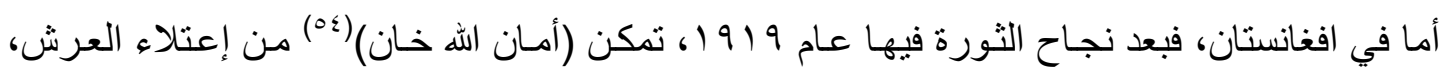

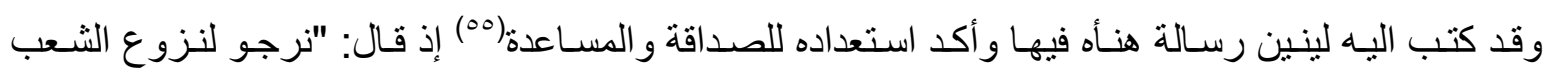

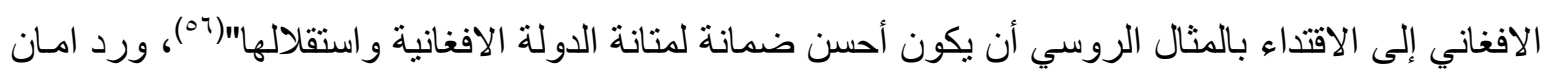

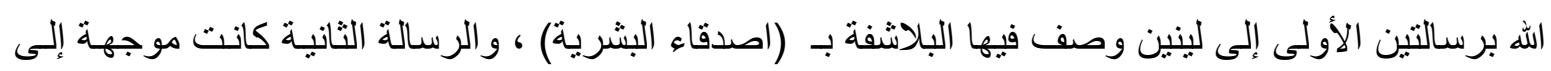

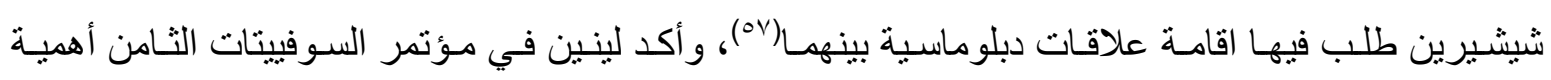


العلاقات مع افغانستان و إنها في حالة تقدم، إذ قال: "ينبغي ان نشير إلى ان علاقاتنا الودية تنتظم وتتوطدت

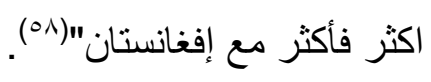

إستمرت الإتصالات بين الدولتين، وقد وصف لينين إفغانستان في إحدى رسائله إلى أمان الله خان بأنها الدولة الإسلامية الوحيدة المستقلة، وأن عليها مهمة توحيد الثعوب الإسـامية، و النهوض بها من أجل التمرد و الإستقلال ورحب باقامة العلاقات بين الطرفين قائلاً: "نرحب بعزم جلالتكم على إقامـة علاقات وثثقة مـع الثعب الروسي، نطلب اليكم ان تعينوا ممثلاً رسمياً في موسكو، ونعلن بدورنا استعداداً لإرسال ممثل لحكومة العمال و الفلاحين في كابول"(ه9)، و اتجهت العلاقات بين الطرفين إلى تبـادل المبعوثين وإجر اء المفاوضـات

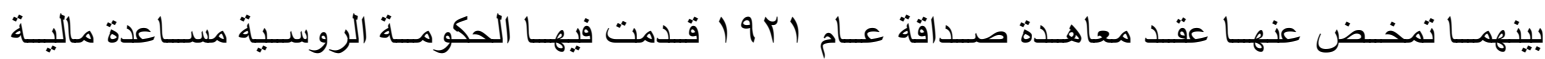
لأفغانستان (7.).

وتعززت العلاقة بين الطرفين، لاسيما الجانب الأقتصـادي، وتم إبرام اتفاق تجاري بينهمـا، وتطورت العلاقة حتى وصلت عام § 19 إلى حد المساعدة العسكرية التي قدمها الاتحساد السوفييتي لأفغانستان عندما حصل تمرد في (أقليم خوست- Khost) ضد الحكومة المركزية، إذ اشترك طيارون سوفيت في القضاء على

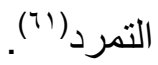

أما سياسة لينين الخارجية تجاه العالم العربي فقد وجها لينين نداء إلى المسلمين لاسيما العرب وحثهم

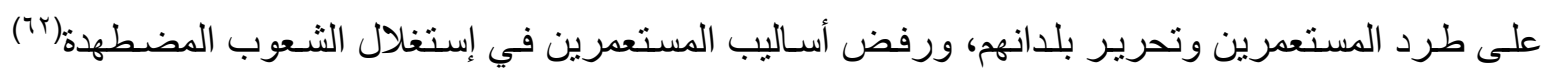
قائلاً: "إن سياسة البروليتاريا الخارجيـة فهي السير في تحسالف مـع الثوريين في البلدان المتقدمة ومـع جميع

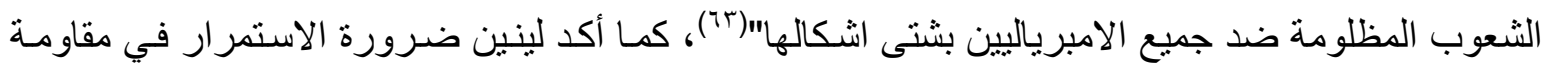
المحتل مهما بلغت قوته العسكرية قائلا: "أن الحرب الثوريـة التي تشنها الثـعوب المظلومـة مهمـا بلغت هذه الثـعوب من الضـف ومهمـا بـدت قوة الظـالمين الأوربيين الذين يستخدمون جميع معجزات التكنيك و الفن

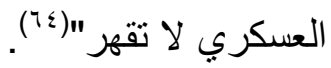
و عند قيام الثورة المصرية 919 (1 اعلن لينين تأييده لها، وبعث رسـالة إلى (سعد زغلول)(70) قائد الثورة وز عيم حزب الوفد عرض عليه المساعدة العسكرية(74). ولكن سعد زغلول رفضها لتخوفه من المملكة المتحدة رفضده جعل مصر مركزاً للصر اع بينها وبين روسيا. كمـا أيد لينين الانتفاضـة في جبل الزاويـة في ولي

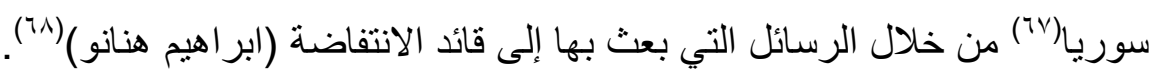
أما العر اق فقد أكد تقرير بريطاني أن لينين دعا الى ضرورة مساعدة أية حركة تقوم في العراق هدفها طرد المستعمرين وتحرير بلدهم(79) ، وذكر تقرير بريطاني أخر أن الحكومـة الروسية ارسلت مبالغ ماليـة

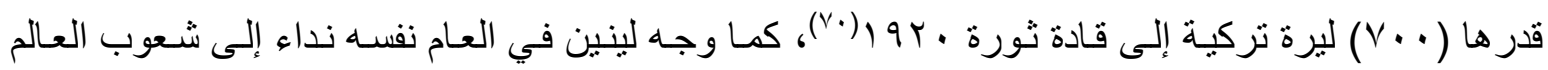

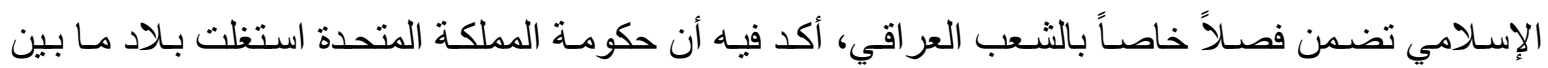
النهرين وسـلبت أر اضـيها، و لابـد مـن مقاومـة المحتـل، وان الحكومـة الروسـية مسـتعدة للمسـاعدة، و أكدات مخابر ات المملكة المتحدة في تقرير لها، ان الحكومـة الروسية دعمت جمعيـة تدعى (الحق) للقيام بالأعمال

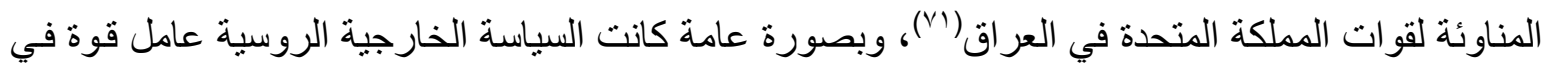


مسـاعدة حركات تحرير الثـعوب من الاستعمار، كمـا ان دعوة لينين للسـلام حفزت الثـعوب على النضـال للتحرر من سيطرة الاستعمار وممارسة حقها في تقرير مصير ها.

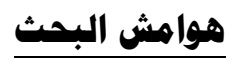

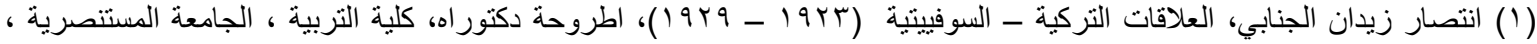

(2) Soviet Documents on Foreign Policy, Appeal of the council of people's commissars to the Moslems of Russia and The East, 3 December, 1917, Kluchnikov and sabanin, P.94.

(3) Глфира, Иран после Первой мировой войны и образование Гилянской Советской республики бзор курса иностранных держав в внешнеполитического отношении Ирана после Первой мировой войны изучение хода развития революционных событий в провинции Гилян. Анализ восприятия персидской политической элитой действий великих держав на Среднем Востоке, Фиджи, Москва, 2012, С. 19 .

(4) Edward Mead Earle , Turkey, The Great Powers and the Baghdad Railway Study in Imperialism , U. S. A ,1924 , PP . 147 - 150 ; Barbara Bennett Peterson, Treaty of Brest-Litovsk in the United States In the Second World War: An Encyclopedia, London, 2012 , PP . $104-105$.

(5) Barbara Bennett Peterson, Op . Cit , P. 105.

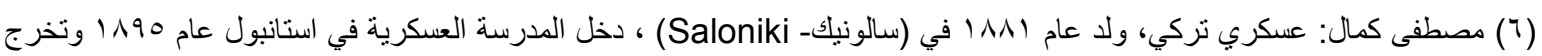

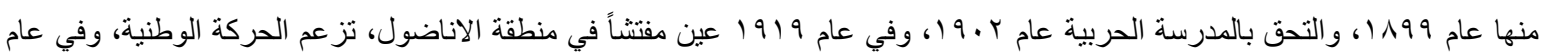

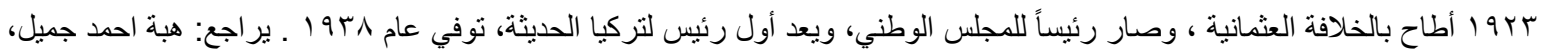

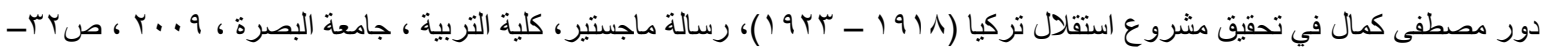

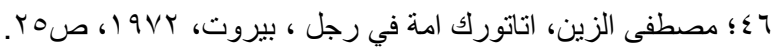

(7) Edward Mead Earle , Op . Cit , PP. 150-151.

(8) George Lenczowaki ,Soviet Advances in the Middle East, Washington 1974, P. 37 .

(9) Barbara Bennett Peterson, Op . Cit , P. 152.

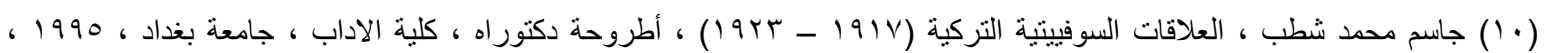
@ IIV-110

David R. Marples, Russia in the Twentieth Century: The Quest For Stability, London, 2014, P . 85 .

(11) J. C. Hurewitz , The Middle East and North Africa in World Politics,

British Franch Supremacy $(1914$ - 1945), London , 1979 , P . 250.

(12) Edward Mead Earle , Op . Cit , PP. 153-154

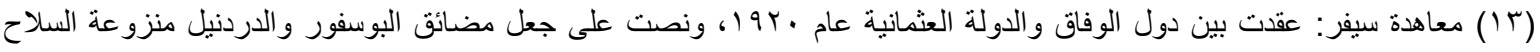
وتشرف عليها عصبة الامم، وعدّت المعاهدة ارمينيا وشبة الجزيرة العربية مناطق مستقلة، ومنحت منطقة تر اقيا إلى اليونان، ولكن حكومة

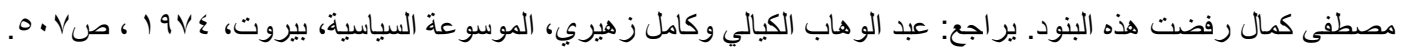
(14) J. C. Hurewitz , Op . Cit , P . 256.

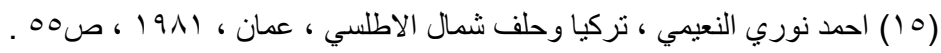

(16) Jon Jacobson, When The Soviet Union Entered World Polities, California, 1994, P . 76 ; David R. Marples , Op. Cit , PP. 85-86. 
(17) Yusuf Hikmet Bayir, Turkiye Devletinin Dis Siyasasi , Istanbul , 1942,P . 70 ; Jon Jacobson, Op . Cit, P. 76 .

(18) J. C. Hurewitz , Op . Cit , P . 257.

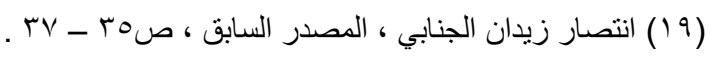

(20) Michael Graham Fry and Erik Goldstein, Guide to International Relations and Diplomacy, New York, 2002, P.213.

(21)R. D. Mclaurin , The Middle East in Soviet Policy, London, 1975, PP.

4-6 ; Michael Graham Fry and Erik Goldstein , Op . Cit , PP. 214- 215.

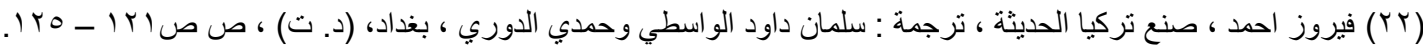

(23) Yusuf Hikmet Bayir , Op . Cit , P.78;

$$
\text { انتصار زيدان الجنابي ، الدصدر السابق ، ص10 } 0
$$

(24) R. D. Mclaurin, Op. Cit, P. 8-9; Michael Graham Fry and Erik Goldstein , Op . Cit , P.215.

(25) Deon Geldenhuys, Isolated States: A comparative Analysis, New York, 1990, PP.86-87;

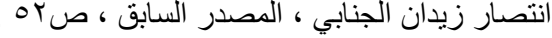

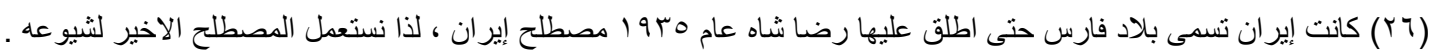

(27)Quoted in:A. Beryozkin and Others, History of Soviet Foreign Policy (1917-1945). Vol . I , Moscow, 1969 , PP . $39-40$.

(28) Soviet Documents on Foreign Policy, Draft Russian Proposal at the Brest Litovsk conference on the future of the accupied territories, December, 1917, P.28.

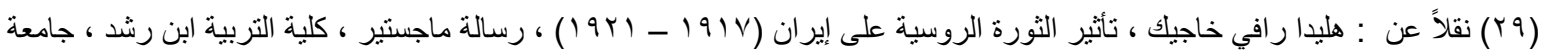

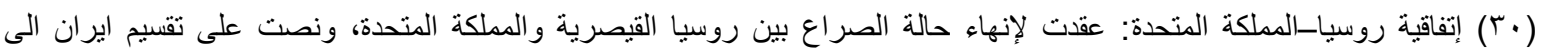

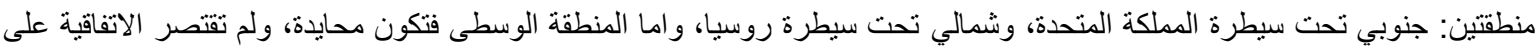

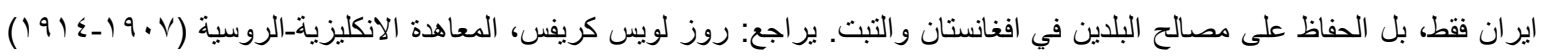

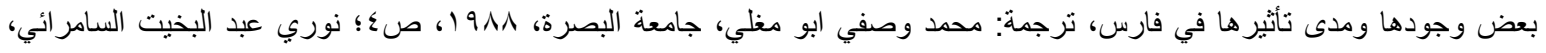

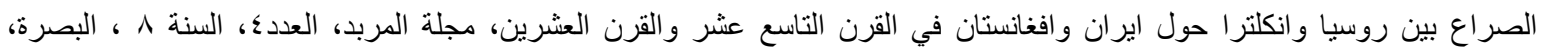

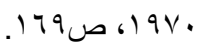

(31)David Skvirsky, Milestones of Soviet Foreign Policy (1917 - 1967),

Translated From Russian, Progress Publishers, Moscow , 1967 , P . 36 .

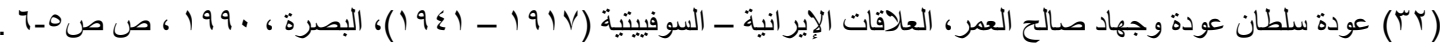

(33) Soviet Documents on Foreign Policy, Statement By Trotsky on the publication of the secret Treaties 22 November, 1917, P.64.

(34) A. Beryozkin and Others, History of Soviet Foreign Policy (1917- 1945) Vol. I, Moscow, 1969, P. 43 .

(35) David Skvirsky , Op . Cit , PP . 37-38 .

(36) Bradley Jahan Boroujerdi , Constitutionalism Social Democracy and

Nationalism and the First Communist Movement in Iran (1905 - 1921),

A thesis Submitted to the Graduate School of Arts of Texas University, U. S. A , 2006 , P .71

(37) Рейснер, русская революция (1905-1907) годов и пробуждение в Азии, народов журнал Советское востоковедение выпуск 2, М., 1955, С.10.

(بر) (براجع : نصوص المعاهدة في : 
Documents of British Foreign Policy, (1919-1939), First series1919, Vol, IV, London, 1952, PP.110112; A. Beryozkin and Others, Op . Cit, P. 145.

(39)L. P. Elwell - Sutton , " Nationalism and Neutralism in Iran ", Middle

East Institute, Vol . XII , U . S. A , 1958, P. 17.

(40)Иванова, влияние Великой Октябрьской революции и движения в

национально-освободительного развитие Иране (1918-1922), г. М., 1957 , C. 333 ; L. P. Elwell - Sutton, Op . Cit , P. 16.

(41)Louis Fischer, Gandi Stalin Two Signs at the Worlds Crossroads, First

Edition Harper and Brothers Publishers, New York, 1947 , P . 74.

(42)Cosroe Chaqueri, The Left in Iran (1905 - 1940): Revolutionary History Series, Vol . 10 , U. S. А , 2001, Р. 13; Иванова, Там же, СС.333-334; Bradley Jahan Boroujerdi, Op . Cit , Р . 70 .

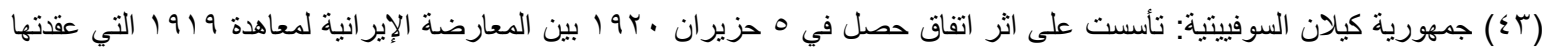

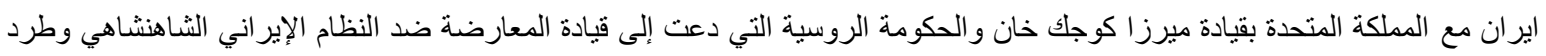

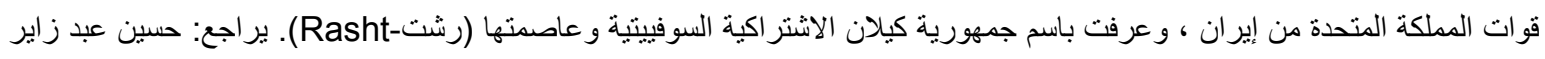

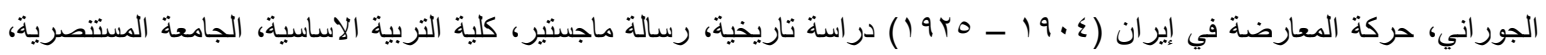

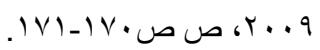

(44)A. Beryozkin and Others, Op . Cit, P . 146.

(45)Иванова, Там же, CC.333-334; Louis Fischer, Op . Cit , PP . 75-76; Cosroe Chaqueri, Op . Cit , Vol . 10 , P.14.

(T؟) خطاب لينين في مؤتمر السوفييتات الثامن لعامة روسيا، في: لينين ، حركة شعوب الثرق الوطنية التحررية، موسكو، (د.ت)،

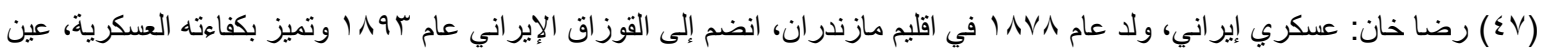

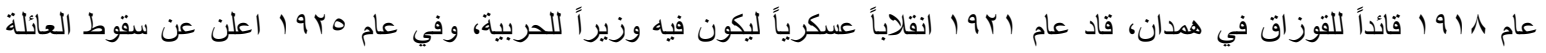

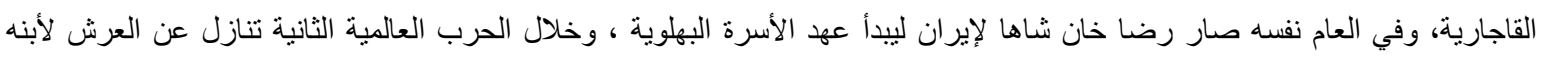

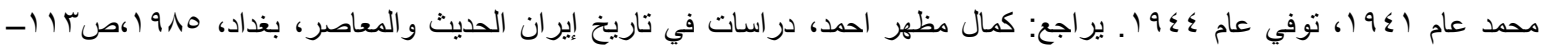

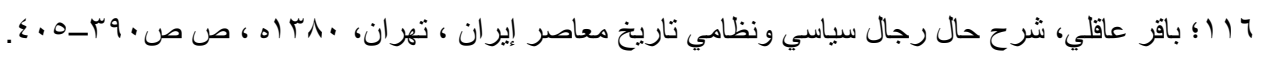

(48)David R. Marples , Op . Cit , PP . 84-85.

(49)Реваз утургаури, поКЕР САЯТОЛЛой Записки консула в Иране, отпечатано в ООО «Веста» Грузия, Тбилиси, 2010 , С. 39 ; David R. Marples , Op . Cit , P . 85 ; Т. А. Воробьева, там же, СС . 49 - 50 ;

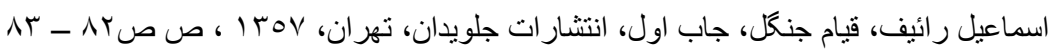

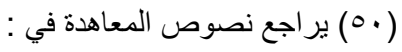

ДВ.П.С, Армия и общество (1900-194)1rr: Статьи и Документы РАН и Ин-т рос; истории Редкол В.П Дмитренко(отв Ред) и др., М., 1999,СС. 377-378; Т. А. Воробьева, там же, СС . 49 - 52; David R. Marples, Op . Cit, PP. 85-87.

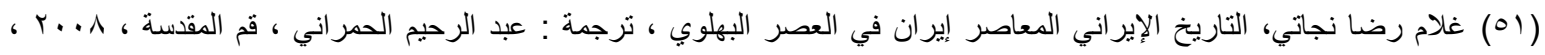

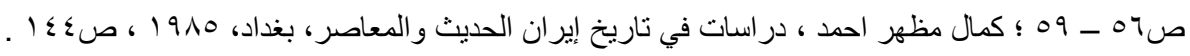
(52)Иране, Реваз отпечатано Тургаури, в ПОКЕР 000 с «Веста» Аятоллой зия, записки Тбилиси, консула 2010 , С. 40 .

(53)A. Beryozkin and Others, Op . Cit, P . 249. 


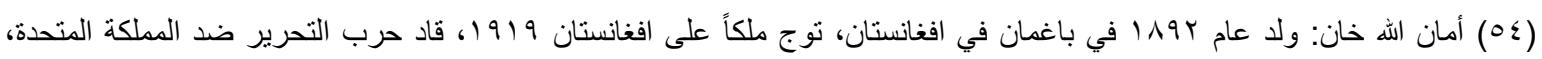

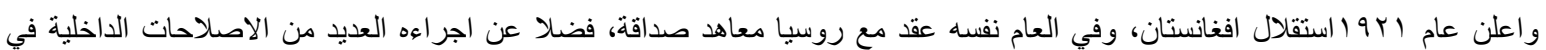

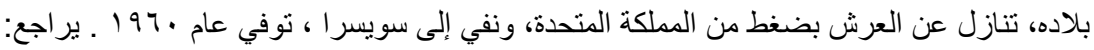
http //ar. M. Wikipedia , Wiki; لينين، حركة شعوب الثرق الوطنية التحررية، صل .0.

(00)Adeeb Khalid, Nationalizing the Revolution in Cental Asia "The Trans

For Mation of Jadidism (1917 - 1920) " , Oxford , 2001 , PP . 150 - 153.

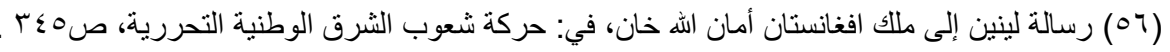

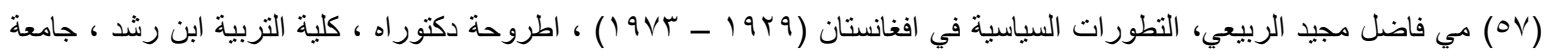

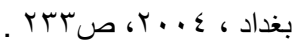

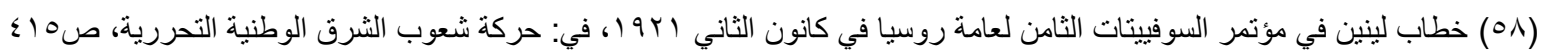

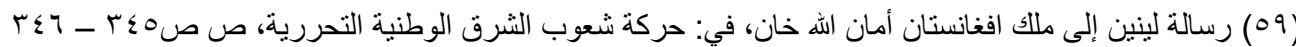

(60)Adeeb Khalid, Op.Cit , PP. 153-155; David R. Marples , Op.Cit, P.85;

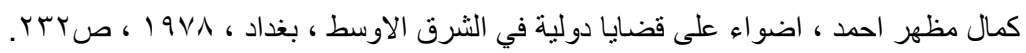

(61)Jon Jacobson , Op . Cit , P . 76 ;

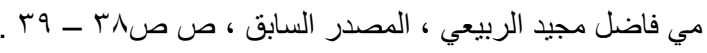

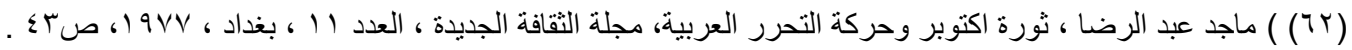

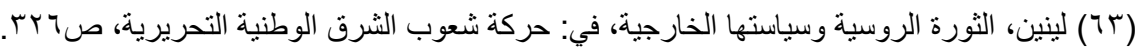

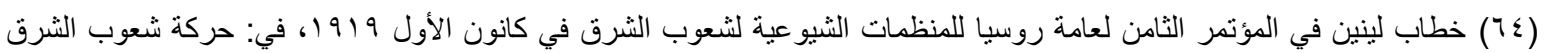

الوطنية التحررية، صسمب.

(10) سعد زغلول: سياسي مصري، ولد عام .117 في ابيانا في مصر، درس في الجامع الازهر و أكمل تعليمه في كلية الحقوق، عمل في

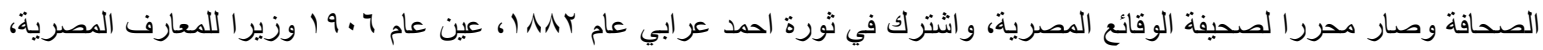

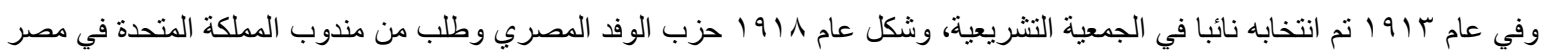

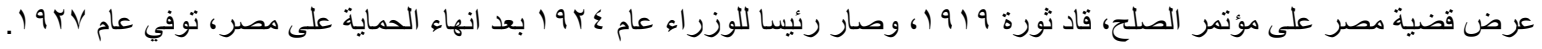

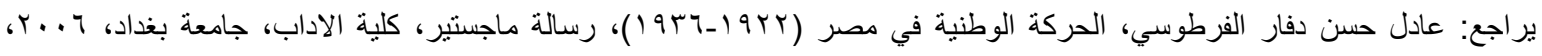

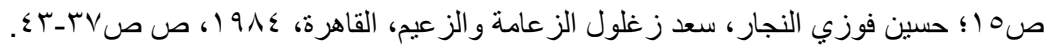

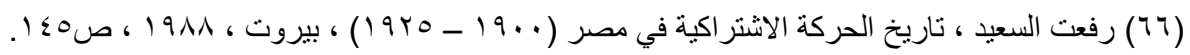

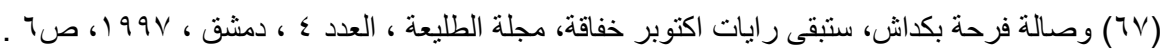

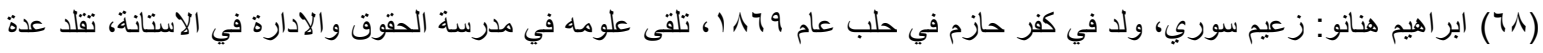

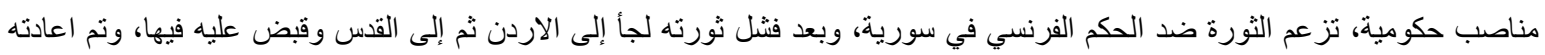

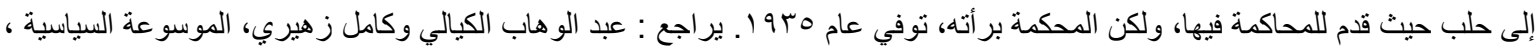

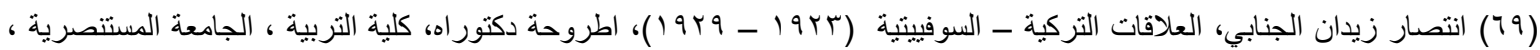

(70) Documents of British Foreign Officer, 371/5228 / E 9849 , From The Civil Commissioner Baghdad, 1920 , P . 22 .

(71) Documents of British Foreign Officer, 371/6349 / 2172, Mesopotamia Intelligence Report, 1920, P. 4. 